\title{
A informação essencia a vida, as máquinas e a comunicação
}

\begin{abstract}
Sebastião Carlos Squirra ${ }^{1}$
Resumo: A informação constitui a razão da existência, sendo referência para o universo, a natureza e os seres e confere significados às ciências, às matérias e à consciência do homem, sendo conceito essencial para a comunicação. Neste texto, apontamos que ao se instalar na Sociedade do Conhecimento, o conceito inseriu configurações com elementos de significação mais abrangentes, pluralizados e interligados. Com referências diversificadas, avaliamos que a reconfiguração traz contribuições para a comunicação, pois centrada nas tecnologias e nas cognições que advieram, inéditas configurações e aplicações se instalaram. Além dos meios tradicionais, os acessos com multi displays, realidade aumentada, bancos de dados nas nuvens, holografias, entre outros. são volumes gigantescos de informação que se disponibilizam e transitam, confirmando que a informação tudo permeia e significa.
\end{abstract}

Palavras-chave: informação; comunicação; mídias digitais.

\begin{abstract}
Information is the reason of existence, with reference to the universe, nature ant the beings and gives meaning to science, materials and man's conscience, being a essential concept for communication. In this paper, we point out that when installing in the Knowledge Society, the concept inserted configurations with broader, pluralized and interconnected significance. With diversified references, we evaluated that the reconfiguration brings contributions to communication, as focused on technologies and cognitions, original applications are installed. In addition to traditional media, access to multi displays, augmented reality, databases in the cloud, holograms, among others are huge volumes of information thai is available and transit, confirming that the information pervade and signify.
\end{abstract}

Keywords: information; communication; digital media

\section{Introdução}

A informação está presente em tudo, nas estruturas cósmicas, nos padrões da natureza, nos compostos minerais, na microfísica dos organismos

${ }^{1}$ Prof. Dr. no Programa de pós-graduação da Universidade Metodista de São Paulo. Email: ssquirra@gmail.com. 
vivos, nos protocolos do mundo vegetal e também embutida na dimensão metafísica. De fato, todo conhecimento começa com a informação. Assim pensa o filósofo da mente Fred Dretsker ao afirmar que "no princípio havia a informação. O verbo veio depois" conforme citado por James Gleick (2013, p. 332). Entendemos que a informação estrutura a experiência humana em seus processos de elaboração de conceitos a partir da observação do universo, da decodificação do meio ambiente, o mundo animal e os sintomas da alma. A informação se manifesta na simbiose do homem com instrumentos, iniciativa que data do longo processo interativo em que, ao distanciar-se dos seus antepassados, o homo sapiens sapiens assumiu trajetória própria nos primórdios da racionalidade. Intuitivamente, nossos ancestrais perceberam que ao ancorar compreensões no meio ambiente (um território pleno de informações), uma sistematização racional surgia e ampliava os sentidos cognitivos, fazendo emergir as condições mentais que abririam campo para a incidência dos lampejos de inteligência, atributo que o distinguiria dali para frente. Com o tempo, evoluídas racionalidades fluíram e se configuraram como fundamentais para a defesa territorial, a garantia da sobrevivência e ainda a plantação, estocagem, aumento da produção e deslocamentos das tribos. E, muito à frente, para se comunicar.

\section{A Informação e os seres humanos}

Há muito tempo cientistas procuram entendimentos da linha da evolução humana, tendo como vertente analítica a compreensão das caraterísticas das suas partes física e mental. Para Descartes, a mente e o corpo se configuram como entidades distintas, como explicitado no livro Meditações (1641) onde este filósofo afirmou que as ideias (de fato, informações sendo elaboradas) surgem de 3 maneiras: a) derivadas da experiência; b) inferidas a partir da razão e c) de maneira inata (criada na mente por Deus). Com tais atributos, a observação e o pensamento aplicados na iteração ${ }^{2}$ permitiram a elaboração das extensões corpóreas que asseguraram o deslocamento, a sobrevivência e o progresso, fazendo com que os instrumentos passassem a ter papel fundamental nesse processo. No livro Leviatã (1651) o filósofo Thomas Hobes não acolheu a ideia

${ }^{2}$ Procura do acerto no processo de tentativa e erro 
da existência das duas dimensões de Descartes, corpo e alma, apesar de aceitar que "alguns corpos são imperceptíveis, ainda que ocupem espaço físico e tenham dimensão física" conforme exposto no Livro da filosofia (2011, p.115). Para Hobes, homens e animais podem ser entendidos como máquinas de carne e osso.

Focamos a informação como forma de elaboração cognitiva que inicialmente se estrutura como processo mental e entendemos que a informação integra todos os sistemas lógicos existentes, sem os quais não seriam possíveis tanto as relações cósmicas, orgânicas e minerais quanto as inter e intrahumanos. $\mathrm{O}$ recorte inter-humano diz respeito às dialogicidades entre pares que identificam a raça, como seres sociais que são. $O$ intra-humano refere-se aos processos biológicos no íntimo dos corpos, adicionando o que James Gleick diz que "a informação é aquilo que alimenta a funcionamento do nosso mundo: o sangue, o combustível, o princípio vital" (2013, p. 16)". Este autor lembra ainda que "até a biologia se tornou uma ciência da informação, sujeita a mensagens, instruções e códigos", (2013, p. 16), arrematando que "a própria evolução é o resultado de uma troca contínua de informações entre organismo e meio ambiente" (2013, p. 17).

Séculos atrás cientistas passaram a aceitar que existia paralelismo funcional entre corpo e as máquinas e a primeira obra com tal tipo de análise foi $O$ homem-máquina ${ }^{3}$, livro escrito em 1748 pelo médico francês Julien Offray de la Mettrie, considerado um precursor da ciência cognitiva. Mettrie (também em MATTELART, 2002, p.26) encarava a relação da alma com o corpo a partir do entendimento do funcionamento das máquinas, que recebem matérias básicas (oxigênio, carvão, óleos, querosene, eletricidade etc.) e transformam estes insumos em trabalho. Para Gleick (2013) Mettrie analisava o corpo como um enorme e metódico processador de informações. No mesmo sentido, para Mattelart "a analogia da máquina alterna-se então com a do ser vivo para determinar o conceito de 'sistema"' (2002, p.26), resgatando a definição de Mettrie de que "o corpo individual é um imenso relógio; o corpo coletivo, um

3 Disponível em http://www.olimon.org/uan/La-Mettrie-El-Hombre-Maquina.pdf. Acessado em 05.01.2015 
maquinismo cuja organização responde a uma mecânica da mesma natureza”(2002, p.26).

Outro cientista importante foi o médico judeu alemão Fritz Kahn, que explicava o funcionamento do corpo humano a partir de desenhos que retratavam as atividades dos órgãos como se fossem uma fábrica repleta de equipamentos. Sua maior obra foi Fritz Kahn o homem máquina (2013), originalmente publicada em 1926 com título original de Der mensch als industrieplast (O homem como um palácio industrial). Na introdução Steven Heller adianta que "Kahn descobriu um caminho ao visualizar dados décadas antes da visualização tornar-se um método reconhecido no processamento e interpretação da informação" 4 (tradução nossa, 2013, p. 7). Como um cientista avante da sua época, Kahn foi esquecido longo tempo pois, como judeu, foi perseguido na Alemanha nazista. Sua obra e importância foram resgatadas quase por acaso, em 1983, conforme relata o jornalista Alvaro Corcuera, do jornal El País 5 . Estes antecedentes nos mostram que o entendimento do homem como estrutura racionalizada e espelhada nas máquinas são antigos, elucidativos e instigantes e trazem questões relevantes.

São também importantes pois se efetivam nos processos da comunicação, já que estes recortam território no qual a informação constitui essência cognitiva humana majoritária. Dessa forma, no presente texto recortamos os fenômenos informacionais que ocorrem nas relações interativas dos seres com as máquinas, em encadeamento que elabora e endereça sentidos nas narrativas e formas de produção de conteúdos. Tal delineamento tem tomado tempo nas construções teóricas de várias correntes e nas discussões filosóficas de muitos autores, uma vez que estudos sobre o homem e sobre máquinas perpassam os séculos. A cultura teórica ai obtida introduziu estudos em campo denominado IHC, termo próprio para as interações homem-máquina. Esse espaço acadêmico/profissional estuda as questões de usabilidade e a relação lógica dos

\footnotetext{
4 No original "Kahn found an eye for visualizing data decades before data visualization become a recognized method for processing and interpreting information

5 Disponível em http://elpais.com/elpais/2013/o8/30/eps/1377855243 760170.html. Acessado em 11.12.2014
} 
homens quando estes interagem com toda sorte de máquinas, sejam estas individuais ou industriais, simples ou complexas, conectadas ou isoladas.

\section{Efetivamente, tudo é informação}

A elaboração racional humana estabeleceu formas sequenciais de ordenamento ao conhecimento e elaborou sentido à vida, impulsionando o surgimento e a consolidação da matemática e da lógica, o que favoreceu a criação das ciências, que se incumbiram de explicar os mistérios da espécie e as relações simbióticas desta com máquinas e meio ambiente. Nesse processo, a razão se impôs abrindo espaço para que Leibniz viesse a assegurar que "todo conhecimento vem da reflexão racional", citação presente no Livro da filosofia (2011, p.137). De fato, Leibniz, filósofo e matemático, investigou a natureza da lógica, e conforme Mattelart lembra, este campo "marca efetivamente uma parte essencial da ideia segunda a qual o pensamento pode se manifestar no interior de uma máquina" (2002, p.12). Tal realidade subsidia a sociedade com a oferta de facilidades e solução de problemas no convívio coletivo com equipamentos e sistemas que, por criativos, inovativos e eficientes, se tornaram perenes, integrados e inteligentes. A sociedade adotou a linguagem (há milênios) e a comunicação amplificada, formas que vêm sendo suportadas por aparatos tecnológicos que acondicionam conteúdos em profusão de endereçamentos individuais ou coletivos, exponenciando sistemas em dimensão e velocidade impensáveis até poucas décadas. Tudo comandado pelo cérebro humano.

Os construtos comunicativos são formas codificadas de sentidos cognitivos que se materializam em discursos, sendo estes essencialmente constituídos por elementos de informação. A informação substancia a raça e está gravada na identidade da espécie, tendo sido inserida na cultura humana quando o cérebro evoluiu e expandiu os processos sinápticos, incorporando o raciocínio estruturado. Tal ampliação da constituição biológica estruturou a capacidade lógico-organizativa, dando condições a Charles Seife de asseverar que, de fato, tudo é informação indo das "regras que governam o movimento dos átomos num pedaço de madeira" (ao citar a termodinâmica) à relatividade que "descreve como objetos se comportam em velocidades extremas e sob a 
forte influência da gravidade", passando pela teoria quântica "que governa a esfera do muito pequeno" (2010, p. 8). Para Seife a informação "é tão real e concreta quanto massa, energia e temperatura" (2010, p.15), adicionando que ela

parece estar na essência dos paradoxos mais profundos da ciência os mistérios da relatividade e da mecânica quântica, a origem e o destino da vida no universo, a natureza do poder destrutivo do buraco negro, e a ordem oculta num cosmo aparentemente ao acaso (2010, p. 9).

Alargando a abrangência do termo, Charles Seife, advoga que "a vida, também é moldada pela informação. Todas as criaturas vivas são máquinas processadoras de informação em algum nível; criaturas inteligentes, conscientes, estão processando essa informação em suas mentes assim como em suas células". (2010, p.294). O processo básico que acontece no corpo humano é a elaboração de conexões, pois conforme adiciona Nicolelis "populações de neurônios são os verdadeiros compositores das sinfonias elétricas que dão vida a todos os pensamentos gerados pelo cérebro humano" (2011, p.21). Corroborando a afirmação, Seife adiciona que

cérebros são máquinas processadoras de informação e estão sujeitos às leis da informação. A teoria da informação clássica implica que somos meras máquinas extremamente complexas de processamento de informações. Isso significaria que não somos fundamentalmente diferentes de uma máquina de Turing ou de um computador (2010, p. 237) .

Este autor arremata afirmando que

nós, seres humanos, armazenamos informação nos nossos cérebros e nos nossos genes assim como os computadores armazenam informação em seus discos rígidos. $\mathrm{E}$, de fato, parece que o ato de viver pode ser visto como o ato de replicar e preservar informação apesar das tentativas da natureza de dissipá-las e destruí-las. A teoria da informação está revelando a resposta à velha questão: o que é a vida? Essa resposta é bastante perturbadora” (2010, p. 101).

Nessa linha de raciocínio, a evolução impulsionou o conhecimento e, com superação constante, direcionou soluções inovativas para realidades dependentes de leque abrangente de tecnologias. Em processos de substituição 
persistentes, os recursos técnicos conduziram às sociedades fortemente conectadas e em sistemas de redes plenos, fazendo com que confluíssem para os gigantescos níveis de acesso e intercâmbios de dados da contemporaneidade. Na estrutura social que aflorou e é presente, tornou-se pertinente reolhar a informação enquanto conceito distinto daquele usualmente entendido, já que pelas inéditas abrangências, vem requerendo novas angulações teóricas. Apontamos a própria hermenêutica do termo, uma vez que este experimentou ampliação conceitual o que provocou sua expansão semântica. Tal proposição se justifica, pois a informação é referência para o cosmos, para a existência biológica e para todos os processos da natureza, não se restringindo a um predicado exclusivo de área acadêmica ou profissional. Tal assertiva se alicerça, pois a base cognitiva foi reconfigurada com a consistente inserção das inúmeras tecnologias, reforçando-se aquelas conectadas, que trouxeram inéditas formas de materialização de informações, sobretudo com as novas plataformas, como os tablets, os celulares inteligentes etc. e as formas visuais que surgiram, como a holografia, as imagens da realidade virtual etc. Isto, somado à transmissão de conteúdos que poderá mesmo prescindir dos suportes midiáticos, em situações nas quais a comunicação se estabelece entre mentes, no que Nicolelis chama de "brainets", para redes mentais (2011, p.25). Tais possibilidades reforçam Charles Seife quando este diz que "físicos e biólogos começaram a compreender que as ideias da teoria da informação governam muito mais do que bits e bytes de computadores, códigos e comunicações: elas descrevem o comportamento do mundo subatômico, toda a vida na Terra e até o Universo como um todo". (2010, p. 9)

Ancorados em Seife de que a "ideia de comunicação nasceu da antiga arte de codificação e decodificação" (2010, p. 8), reforçamos o princípio de que tudo é informação: dos buracos negros às células que compõem o corpo humano; dos dados estocados nas sementes à evolução do sistema solar; da forma de funcionar de uma máquina à narrativa poético-literária; dos discursos científicos às linhas de comando dos aplicativos; das fórmulas dos remédios ao comportamento da natureza, etc. Corroborando com esse pressuposto, Seife afirma que "cada criatura na Terra é uma criatura de informação; a informação 
está no centro de nossas células, e as informações matraqueiam em nossos cérebros” (2010, p. 9), para em seguida adicionar que

cada partícula do universo, cada elétron, cada átomo, cada partícula ainda não descoberta estão abarrotados de informações informações que são muitas vezes inacessíveis para nós, mas não obstante informações, que podem ser transferidas, processadas, dissipadas. Cada estrela do universo, cada uma das inúmeras galáxias do espaço estão repletas de informação [...] esta informação está sempre fluindo, indo de um lado para outro, espalhando-se pelo $\operatorname{cosmo}(2010$, p. 9).

Seife fala da perenidade da informação e indica que após os físicos combinarem a arte da decodificação com a ciência da termodinâmica, resultou a teoria da informação que, instantaneamente "transformou o campo das comunicações e pavimentou o caminho para a era dos computadores". (2010, p.8), recordando Claude Shannon que fundou a Teoria da Informação em 1948, ao constatar que a informação podia ser medida e quantificada (2010, p. 68). Seife lembra que a aproximação da informação com a comunicação surgiu de um problema prático: "como juntar o maior número possível de conversas telefônicas na mesma linha, ao mesmo tempo, sem que houvesse interferências entre as ligações" (2010, p. 71). Isto, tendo como alicerce que a "comunicação é simplesmente a transmissão de informações de uma pessoa para outra" (2010, p.70). Na procura pela maior eficiência na transmissão de conversas telefônicas, Seife afirma que Shannon "criou a terceira grande revolução da física no século XX: como aconteceu com a relatividade e a teoria quântica, a teoria da informação mudou radicalmente $\mathrm{o}$ modo como os cientistas viam o universo"(2010, p.71).

O termo informação se refere ao envio, de um ponto a outro, de dados codificados e encapsulados em narrativas imbuídas de significados. Como exemplo clássico da transmissão de informação, Seife relata o que fez Paul Revere, pouco antes da deflagração da Revolução Americana, em 1775, sendo que

Assim que os britânicos começassem a se movimentar, o sacristão da Old North Church em Boston [...] poderia ver qual caminho os britânicos tomariam. O sacristão então subiria na torre da igreja e penduraria lâmpadas para comunicar o caminho aos americanos na outra margem. Uma lâmpada significaria que os britânicos estavam 
pegando o caminho mais longo, por terra; duas lâmpadas significariam que estavam atravessando o rio. Uma por terra, duas por mar (2010, p.73).

Portanto, uma lâmpada acesa significava uma coisa e duas outra, trazendo o modelo de ou um significado ( $\operatorname{sim}$ ) ou outro (não), introduzindo a "lógica Booleana que lida com verdadeiros e falsos, sins e nãos, ligados e desligados" (SEIFE, 2010, p.74), o que trouxe o princípio do bit, o digito binário. Shannon usou este termo pela primeira vez e "definiu as bases do que hoje se conhece como teoria da informação”. (SEIFE, 2010, p. 74). Todavia, apesar de a impressão que imperava ser a de que se partia para o domínio da informação, o que se descobriu foi que o terreno era muito amplo e análises cuidadosas deveriam ser realizadas . Nesse sentido, o filósofo Jean-Pierre Dupuy advertiu que "quanto mais nos comunicamos da maneira como fazemos, mais criamos um mundo infernal" (grifo no original) (apud GLEICK, 2013, p.426), introduzindo o princípio da "sobrecarga de informação6, o que nos lembra James Gleick que apontou que a informação também está largamente presente na biologia, ao afirmar que sujeito a mensagens, instruções e códigos,

os genes encapsulam informações e permitem procedimentos para que estas sejam lidas a partir deles e inscritas neles. [...] O próprio corpo é um processador de informações. A memória reside não apenas no cérebro, mas em cada célula. Não surpreende que a genética tenha florescido junto com a teoria da informação. O DNA é a molécula de informação quintessencial, o mais avançado processador de mensagens em nível celular - um alfabeto e um código, bilhões de bits para formar um ser humano (2013, p. 17).

Julien Offray de la Mettrie (1748) e Kahn (2013) entenderam que o corpo humano espelha a complexidade da máquina e Gleick (2013) adicionou que o que a máquina humana essencialmente faz é elaborar e gerenciar informações. Estes, mais Capra (1996) indicam que além dessas qualidades, a informação produzida pelo homem segue um fator que é muito importante: o processo da transmissão das informações está permanentemente conectado em rede. Como diz Gleick, "a vida se expande por meio do estabelecimento de redes" (2013, p.16), seja no organismo, na natureza, nas máquinas ou na sociedade. Para

${ }^{6}$ No original: overloaded of information. 
Mettrie, a rede é o próprio corpo humano. Gleick cita o teórico da evolução Richard Dawkins para quem "aquilo que jaz no coração de todas as coisas vivas não é uma chama, nem um hálito quente, nem uma 'faísca de vida.' É a informação, palavras, instruções", arrematando em seguida que "se quiser compreender a vida, não pense nas gosmas e melecas pulsantes e fluidas e sim na tecnologia da informação" (2013, p.17). Abordar o tema informação nos revelou a necessidade de buscar aportes teóricos também em outros segmentos científicos, pois como informa Gleick, o cientista Rolf Landauer afirmou que "a informação é física” (2013, p.370).

Em A física do futuro (2012), o cientista Michio Kaku aborda a pletora de inovações que está sendo disponibilizada à humanidade, tópicos especialmente úteis para os comunicadores. Essa obra é fruto da longa experiência deste físico, que resgata o papel de visionários como Julio Verne e Leonardo da Vinci advertindo que o futuro é difícil de ser previsto, mesmo para pesquisadores qualificados. $\mathrm{O}$ autor pontua a importância das grandes descobertas como a gravidade, a força magnética, as forças nucleares, a teoria quântica, a biotecnologia, a nanotecnologia, o hiperespaço em 11 dimensões etc. Michio Kaku aponta a extensa proliferação de máquinas movidas a chips e de equipamentos informatizados inseridos em todos tipos de aparatos domésticos, princípio que pelo volume de adoção recebeu o denominação de "computação ubíqua". O autor lembra que tal termo foi criado por Mark Weiser cientista que previu que "os chips um dia serão tão baratos e abundantes que se espalhariam por todo o ambiente" (2012, p. 36). Quanto à incessante proliferação das multitelas, Kaku prevê que "estaremos cercados por monitores de computador, mas eles se parecerão com papéis de parede, molduras de quadro ou fotografias da família e não com computadores" (2012, p. 38). Isto, pois o barateamento e a miniaturização dos equipamentos indicam que "por volta de 2020, o preço de um chip talvez caia para cerca de um centavo, que é o custo de papel rasgado" (2012, p. 39). O autor sugere que passaremos a inserir chips em todas as partes, em todos os equipamentos, em todas as peças, inclusive incrustados no homem na forma de próteses corporais quando "a internet estará por toda parte - em telas na parede, em móveis, em cartazes e até em nossos óculos e lentes de 
contato. Quando piscarmos, estaremos on-line"(2012, p, 40). Os chips e toda sorte de equipamentos que este autor indica simbiotizarão a experiência humana, uma vez que armazenam, codificam, transmitem e decodificam informação.

Cientistas testam novas formas de conexões e constroem equipamentos que permitirão o envio e recepção de informação em redes tão avançadas que foram definidas como internet "das mentes" (KURZWEIL, apud Anderáos, 2006; HALPERN, 2011). Podoly, por exemplo, advoga a possibilidade de uma internet "of $m e$ "(2013) conceito inovador que exponencia aquele de "internet das coisas" (internet of things), revelando que a evolução tecnológica tem sido radical, profunda e constante, onde Michio Kaku prevê que

a rápida ascensão da capacidade computacional lá pelo ano 2100 nos dará um poder igual ao dos deuses da mitologia que adoramos no passado, permitindo-nos controlar o mundo à nossa volta com o simples pensamento (2012, p. 39).

A afirmação é ousada nas parece pertinente, uma vez que já funcionam a contento equipamentos informatizados que identificam e atendem aos pensamentos humanos, como apontam Kurzweil (2007), Seife (2010) e Nicolelis (2011). Nesse sentido, Kaku lembra que as formas de materialização da informação se tornaram tão abrangentes que estão sendo programadas para hibridizarem o corpo humano como próteses biológicas, pois

desde 1991, os cientistas da Universidade de Washington trabalham para aperfeiçoar o display da retina virtual (VRD, virtual retina display)...[...]...com um campo visual de $120^{\circ}$ e uma resolução de $1600 x 1200$ pixels, o display VRD pode produzir uma imagem brilhante, quase real, que se compara com a vista num cinema. (2012, p.41).

Michio Kaku resgata o cientista Babak A. Parviz que previu a construção de lentes de contato com conexão internet e nas quais será possível "baixar qualquer filme, canção, site da web de informação” (2012, p. 42)7 diretamente na retina, não mais sendo necessários os meios que intermediam a comunicação entre emissores e receptores. Além disso, estes recursos permitirão "identificar

7 Disponível em http://www.tecmundo.com.br/saude/49230-google-trabalha-emlentes-de-contato-inteligentes-para-ajudar-diabeticos.htm. Acessado em: 04 fev. 2015. 
pessoas estranhas e conhecer seus antecedentes, mesmo enquanto se fala com elas" (2012, p.42), pois as imagens serão projetadas dentro do olho humano, como imaginado por escritores e mostrado em cenas de filmes de ficção. Kaku advoga que

teremos informações ininterruptas, a qualquer hora, em qualquer lugar. [...] No futuro, você não vai precisar carregar um computador de um lado para outro, visto que, para onde quer que você se virar, as paredes, quadros e móveis poderão conectá-lo à internet, mesmo que você esteja num trem ou carro (2012, p. 49).

Em tempos de pletora tecnológica e informativa, o autor define que na computação nas nuvens, seremos cobrados por tempo de uso dos computadores, uma utilidade que será medida "assim como a água ou a eletricidade" (2012, p.49), adicionando que ao se materializar em aparatos tecnológicos que integram a cognição humana dos dias atuais, a informação se hibridiza ao ser em dimensão antes nunca experimentada. E isto vem de longo tempo.

\section{A informação como síntese comunicativa}

A história da íntima relação do homem com a informação origina-se no intento do intercâmbio de sentidos, em processo comunicativo mediado por articulações tecnológicas que interligam máquinas. Nas pontas da cadeia está o ser humano, emissor ou receptor e, no meio, as máquinas que se conectam e transmitem as narrativas que se materializam em equipamentos audiovisuais no inicio e fim do trajeto. Nesse complexíssimo sistema de codificação e endereçamentos, as inovações trilharam incessante evolução, inserindo condições para que os meios digitais ampliassem o acesso social às informações, rompendo os estratificados pressupostos comunicativos do mundo analógico.

O termo informação é familiar para os comunicadores, por integrar os processos de construção e difusão de relatos com significados à sociedade. Thomas Davenport questiona: "o que é a informação, afinal de contas?” (2001, p.18), advertindo que se deve debruçar sobre as diferenças entre dados, informação e conhecimento e adiantando que "durante anos, as pessoas se referiram a dados como informação; agora, se veem obrigadas a lançar mão de 
conhecimento para falar sobre a informação". Fala de "dados como observações sobre o estado do mundo"' (2001, p. 19) e resgata a definição de Peter Drucker que disse entender a informação como "dados dotados de relevância e propósito" (2001, p. 19).

Na obra História da sociedade da informação (2002), Mattelart aponta que Leibniz foi quem primeiro propôs a adoção do sistema binário, que é a base da informação digital, acrescentando que sistema semelhante vigorou "há 4 mil anos na China de Fo-Hi” (2002, p.16). A quantificação da informação está presente também no livro Informação, linguagem, comunicação, de Décio Pignatari, (1973, p. 51). Depois da navegação por inúmeros autores e teorias, Mattelart foca no conceito de Cibernética de Norbert Wiener ${ }^{8}$ e Claude Shannon9 lembrando que Warren Weaver apontou que Shannon havia advertido que o termo "informação não deve ser confundido com significado (ou compreensão)" (1954, p.8). Por fim, Francis Bacon afirma que "a palavra informação significa o mesmo que inteligência"10 (apud MATTELART, 2002, p.14). Avançando no termo, Emmanuel Dion afirma que o texto de Claude Shannon fundou um novo segmento científico, tornando-se um dos grandes eventos da história da ciência no XX século ${ }^{11}$ (1997, p.11, tradução nossa). Destacamos que a ambiguidade apontada por Michael Buckland aparece na primeira nota de rodapé desta obra, quando Shannon afirmou que

deve-se assinalar que até o momento, de forma bizarra, os dois termos Teoria da Informação e e Teoria da comunicação têm sido indiferentemente empregados para designar exatamente a mesma coisa, a saber, o trabalho fundador de Shannon e seus variados desdobramentos. O mesmo Shannon preferia o termo

\footnotetext{
8 op.cit. p.58

9 op.cit. p. 65

${ }^{10}$ no original intelligence

${ }^{11}$ No original: La publication de l'ouvrage fondateur de Shannon, écrit en 1948, [...] restera, donc, certainement comme l'un des grands événements de l'histoire de la science au XXe. Siècle.
} 
Teoria da comunicação mas o uso corrente consagrou Teoria da informação (DION, 1997, p. 11, tradução nossa) ${ }^{12}$

A informação está ligada aos meios que permitem a sua codificação, encapsulamento e difusão, processo essencialmente suportado por plataformas midiáticas diversas, pois como afirma Dion, ela surgiu modestamente do "trabalho prático de engenheiros que procuravam melhorar a performance de aparelhos físicos de transmissão da informação, e em particular, das linhas de telégrafo" (1997, p.17, tradução nossa) ${ }^{13}$. Para esse autor, a primeira vez que "apareceu a informação enquanto quantidade mensurável foi nos anos 1920, nos trabalhos do célebre investigador inglês Ronald A. Fischer, pai da estatística matemática (1997, p. 20, tradução nossa) ${ }^{14}$, o que antecipava em mais de 20 anos os postulados de Shannon. Estreitamente ligadas, informação e comunicação requerem, coexistem e se concretizam com a mediação das tecnologias, processo que ao inserir as múlti e diferenciadas plataformas, fez surgir a "computação afetiva" e os "sistemas de computação cognitiva". A primeira trata das máquinas planejadas para entender o estado de humor dos humanos, tal como explicitado por Erez Podoly, podendo emergir uma "internet of $m e$ ". Nesse propósito, a cientista Rosalind Picard investiga as "formas de atribuir habilidades emocionais ao computador para que a máquina tenha capacidade de responder de forma inteligente às emoções humanas" (LEAL, 2011, p.57). No segundo caso, os sistemas de computação cognitiva, focam a inserção de competências nas máquinas para que elas possam ter uma das mais distintas qualidades do cérebro humano que são os pensamentos criativos. Investimentos enormes estão sendo feitos no Watson da IBM e avanços

${ }^{12}$ No original: Signalons dès a present que assez bizarrement, les deux termes "théorie de l'information" et "théorie de la communication" sont indifferement employés pour designer exactement la même chose, à savoir le travail fondateur de Shannon et des nombreux développments. Shannon lui-meme préferait "theory de la communication", mais l'usage a consacré : théorie de l'information"

${ }_{13}$ No original: ... du travail pratique d'ingénieurs qui cherchaient a améliorer la performance des outils physiques de transmission de l'information, et en particulier des linhes de télégraphe”.

14 No original: La première apparition de l'information en tant que quantité mesurable a lieu Durant les années 1920 dans les travaux du célèbre chercheur anglais Ronald A. Fischer, père de la statistique mathématique. 
progressivos vêm sendo alcançados ${ }^{15}$, visando enfrentar a questão de descobrir se é possível criar consciência artificial, um refinamento das potencialidades da inteligência artificial.

\section{Inovações tecnológicas na comunicação}

Nas artes da comunicação (criação e difusão de conteúdos por textos, narrativas audiovisuais, imagens estáticas, sonoplastias, grafismos etc.), inovações em aplicativos digitais têm trazido novas possibilidades de expressão, pois a qualidade da definição visual galgou inéditos degraus com as bases de materialização e interação antes não produzidas. Assim sendo, dentre as muitas possibilidades que se concretizaram, desponta a chegada dos enormes bancos de dados (Big data), dos aparelhos de Realidade Virtual (óculos Rift" ${ }^{16}$, Oculus etc.) e a realidade aumentada, onde se destaca a holografia, tecnologia que leva os equipamentos portáteis à visualização tridimensional das narrativas e dos elementos plásticos constituintes das mensagens. Visível nos filmes de ficção, a holografia permite que cientistas antevejam formas inéditas de transmissão de informações com altíssimo valor audiovisual de realismo e portanto, de convencimento, a partir da imersão sensorial dos usuários em realidade $3 \mathrm{D}$ que altera todos os padrões reais até então vivenciados.

O uso da holografia como recurso comunicativo é recente sendo que a comunicação deverá incorporá-la, pois este recurso permite a visualização dos fatos com imagens tridimensionalmente projetadas no espaço em frente ao usuário, ou em braceletes, celulares e relógios, podendo interagir com as mesmas ${ }^{17}$. A primeira transmissão holográfica na TV aconteceu nas eleições de 2008, quando a CNN "materializou” uma repórter em transmissão ao vivo feita de Nova Iorque no dia 05.11.2008. A CNN HD utilizou a telepresença holográfica ao trazer a repórter Jessica Yellin, que estava em Chicago, para o

${ }_{15}$ Disponível em http://www.fastcompany.com/3049022/the-future-of-work/3lessons-ibms-watson-can-teach-us-about-our-brains-biases. Acesso em: 27 jul. 2015. ${ }^{16}$ Disponível em http://gizmodo.com/i-tried-the-new-oculus-rift-and-it-blew-meaway-all-ov-

1637201830 ?utm campaign=socialflow gizmodo facebook\&utm source=gizmodo fa cebook\&utm medium=socialflow Acesso em: 27 jul. 2015.

17 Disponível em https://www.youtube.com/watch?v=wwUcZMfmj-Q. Acesso em: 27 jul. 2015 . 
palco em Nova York, no momento da disputa entre McCain e Obama ${ }^{18}$. Experiência semelhante havia sido testada antes com o jornalista Anderson Cooper que entrevistou o cantor Will.I.Am ${ }^{19}$. Esta possibilidade permite a oferta de informações visuais muito mais sedutoras e confiáveis e estão presentes em vídeo que antevê as facilidades para 2019²0. Em 2014, cientistas conseguiram produzir imagens holográficas com interação humana na projeção aérea (a imagem se forma no espaço), no que chamaram de "interação tangível em imagem aérea" 21 , com sistema que funciona em princípio "realizado por laser focalizado" 22 .

Os Bancos de dados (Big data) surgiram com a revolução digital e o mundo inter e intra conectado em grandes velocidades, a partir do uso de pletora inimaginável de equipamentos e aplicativos. Ao afirmar que "Banco de dados significa muito mais que vastos repositórios de dados e softwares exóticos"23 (tradução nossa), o consultor Philip Evans pontua que o volume de "transmissão de dados através das redes de fibra ótica dobra a cada nove meses [..] e a densidade dos arquivos duplica a cada 13 meses" 24 (tradução nossa) ${ }^{25}$. No intento de dimensionar a força deste segmento, Evans indica que "o acesso a internet em banda larga no G-20 está aumentando de 800 milhões (dos quais $50 \%$ em equipamentos móveis) em 2010, para 2,7 bilhões (com 80\% em

${ }^{18}$ Disponível em https://www.youtube.com/watch?v=thOxW19vsTg. Acesso em: 23 dez 2014.

19 Disponível em https://www.youtube.com/watch?v=deoOTqT-SMI. Acesso em: 23 dez 2014.

2o Disponível em https://www.youtube.com/watch?v=TfpgBJPR8Zo. Acesso em: 23 dez 2014.

${ }^{21}$ No original: tangible aerial image interaction

22 No original: rendered by focused laser

${ }^{23}$ No original: 'Big data' means much more than vastly larger data sets and exotic softwares

24 Disponível em https://www.bbvaopenmind.com/en/5-data-about-bigdata/?utm source=facebook\&utm medium=techreview\&utm campaign=MITcompan y\&utm_content=5bigdata. Acesso em: 23 dez 2014.

25 No original: The amount of data transmittable through an optical fiber doubles every nine mounts. [...] Storage density doubles every 13 monts. 
aparatos móveis) em $2015^{26}$ (tradução nossa). Entre outros dados robustos, diz que "o número de celulares no mundo é atualmente igual ao número de pessoas", o que possibilita que "4,5 bilhões de 'likes' sejam postados diariamente. ${ }^{27}$ Tudo isto representa uma imensidão de informação.

\section{Conclusões}

Trabalhamos com o princípio de que a informação é um conceito que merece ampliação teórica, pois tornou-se muito maior do que era, uma vez que sua definição corrente foi estabelecida na realidade do mundo analógico e a transição para uma realidade plenamente digital requer novos enquadres científicos alargando os recortes cognitivos. Assim, ao revisitar o termo, constatamos que tudo se amplia, se metamorfoseia, se redimensiona na realidade digital, evidenciando que o processo dialógico que elabora, transporta e difunde conteúdos informativos se reconfigura, se refaz, se amplia e se resignifica com as novas tecnologias, pois mesclam áreas do saber até então isoladas.

Dessa forma, e ancorados em bibliografia que transborda aquela da comunicação, buscamos recontextualizar o termo, convencidos que o alargamento analítico é justificável e pertinente, pois a sociedade se encontra imersa em evoluída realidade onde um incisivo processo de intercâmbios de significados se efetiva robusta e infindavelmente. Comparativamente, pode-se dizer que na arte do processamento e transmissão de informações, a formulação anterior representa a dimensão de um planeta, enquanto que ao nos afastar e focar o que de fato já está estruturado, encontramos a amplidão dos multiversos, que equaciona tanto as macro dimensões da astronomia (anos-luz) quanto a nanoescala da física quântica (quasars e íons). Assim, antevemos que para os cientistas, sobretudo os da comunicação, se projeta a oportunidade de alargamento conceitual em novas matrizes investigativas. Nos orientamos na convicção de que o ato de suplantar limites converge segmentos investigativos

${ }^{26}$ No original: Broadband internet access in the G-20 is growing from 800 million (of which 50\% mobile) in 2010, to 2,7 billion (of which 80\% mobile) in 2015 .

${ }_{27}$ No original: 4,5 billion 'likes' are posted daily 
acopláveis, refinando as compreensões científicas e espelhando que, de fato, a informação é tudo.

\section{Referências}

ANDERÁOS, Ricardo. O profeta das máquinas espirituais. Folha de S.Paulo/Link. 13.11.2006, p. L10

BLISS Jr, Edward. Now the News - The story of broadcasting journalism. New York: Columbia University Press, 1991

BRAMAN, Sandra. Defining information - No approach for policymakers. Telecommunications policy, Stoneham, Butterworth \& Co, 1989

BUCKLAND, M. Information and information systems. New York, Praeger, 1991

CAPRA, Fritjof. A teia da vida. São Paulo: Cultrix, 2013

CNN Hologram TV First.. Disponível em https://www.youtube.com/watch?v=thOxW19vsTg. Acessado em 23.12.2014

DAVENPORT, Thomas H. Ecologia da informação. São Paulo: Futura, 2001

DION, Emmanuel. Invitation à la theorie de l'information. Paris: Edition du Seuil , 1997

GLEICK, James. A informação. São Paulo: Schwarz, 2013, 521p.

HALPERN, Sue. Cérebro: no controle ou controlado? OESP/Link/The New York Review of books. Disponível em http://blogs.estadao.com.br/link/cerebro-no-controle-ou-controlado. Acessado em 12.04.2014

KAKU, Michio. A física do futuro. Rio de Janeiro: Rocco, 2012, 415 p.

KAHN, Fritz. O homem-máquina. Koln: Taschen, 2013, 391 p.

KURZWEIL, Ray. A era das máquinas espirituais. São Paulo: Aleph, 2007

HEAD, S. e Sterling, C. Broadcasting in America. Boston: Houghton Mifflin Co., 1990

LEAL, Renata. Máquinas têm sentimentos? Revista Info, Abril 2011, p.57

MATTELART, Armand. História da sociedade da informação. São Paulo: Loyola, 2002

NICOLELIS, Miguel. Muito além do nosso eu. São Paulo: Cia das Letras, 2011.

O LIVRO DA FILOSOFIA. Rio de Janeiro: Globo, 2011

PIGNATARI, Decio. Informação, linguagem, comunicação. São Paulo: Perspectiva, 1973 
PODOLY, Erez. The next front of wearables. Disponível em: <http://techcrunch.com/2015/o1/28/the-next- front-of-wearables/> Acessado em 23.04.2015

SEIFE, Charles. Decodificando o universo. Rio de Janeiro: Rocco, 2010

SHANNON, Claude e Weaver, Warren. The mathematical theory of communication. Urbana, University of Illinois Press, 1949

SIQUEIRA, Ethevaldo. Revolução digital. São Paulo: Telequest, 2007

WIENER, Norbert. Cibernética e sociedade - $O$ uso humano de seres humanos. São Paulo: Cultrix, 1954. 